\title{
Neutralization of Inhibitory Molecule NG2 Improves Synaptic Transmission, Retrograde Transport, and Locomotor Function after Spinal Cord Injury in Adult Rats
}

\author{
Hayk A. Petrosyan, ${ }^{1,2}$ Arsen S. Hunanyan, ${ }^{1,2}$ Valentina Alessi, ${ }^{1,2}$ Lisa Schnell, ${ }^{3}$ Joel Levine, ${ }^{2}$ and Victor L. Arvanian ${ }^{1,2}$ \\ ${ }^{1}$ Northport Veterans Affairs Medical Center, Northport, New York 11768, ${ }^{2}$ Department of Neurobiology and Behavior, State University of New York at \\ Stony Brook, Stony Brook, New York 11794, and ${ }^{3}$ University and Eidgenössiche Technische Hochschule of Zurich, Brain Research Institute, CH-8057 \\ Zurich, Switzerland
}

NG2 belongs to the family of chondroitin sulfate proteoglycans that are upregulated after spinal cord injury (SCI) and are major inhibitory factors restricting the growth of fibers after SCI. Neutralization of NG2's inhibitory effect on axon growth by anti-NG2 monoclonal antibodies (NG2-Ab) has been reported. In addition, recent studies show that exogenous NG2 induces a block of axonal conduction. In this study, we demonstrate that acute intraspinal injections of NG2-Ab prevented an acute block of conduction by NG2. Chronic intrathecal infusion of NG2-Ab improved the following deficits induced by chronic midthoracic lateral hemisection (HX) injury: (1) synaptic transmission to lumbar motoneurons, (2) retrograde transport of fluororuby anatomical tracer from L5 to L1, and (3) locomotor function assessed by automated CatWalk gait analysis. We collected data in an attempt to understand the cellular and molecular mechanisms underlying the NG2-Ab-induced improvement of synaptic transmission in HX-injured spinal cord. These data showed the following: (1) that chronic NG2-Ab infusion improved conduction and axonal excitability in chronically HX-injured rats, (2) that antibody treatment increased the density of serotonergic axons with ventral regions of spinal segments L1-L5, (3) and that NG2-positive processes contact nodes of Ranvier within the nodal gap at the location of nodal $\mathrm{Na}^{+}$channels, which are known to be critical for propagation of action potentials along axons. Together, these results demonstrate that treatment with NG2-Ab partially improves both synaptic and anatomical plasticity in damaged spinal cord and promotes functional recovery after HX SCI. Neutralizing antibodies against NG2 may be an excellent way to promote axonal conduction after SCI.

\section{Introduction}

NG2 is a structurally unique transmembrane chondroitin sulfate proteoglycan (CSPG) (Nishiyama et al., 1991; Levine, 1994; Stallcup, 2002). After injury, levels of CSPGs, including NG2, are elevated in the vicinity of glial scar and around injured neurons and their projections in the CNS (Levine, 1994; Zuo et al., 1998; Fawcett and Asher, 1999; Lemons et al., 1999; Jones et al., 2002; Tang et al., 2003; Andrews et al., 2012). This abnormal accumulation of CSPGs is considered a major inhibitory factor that restricts axonal growth following spinal cord injury (SCI) (Snow et al., 1990; McKeon et al., 1991; Dou and Levine, 1994; Davies et al., 1997; Fidler et al., 1999; Silver and Miller, 2004; Galtrey and Fawcett, 2007). Digestion of CSPGs with the bacterial enzyme chondroitinase-ABC (Ch-ABC) (Yamagata et al., 1968) enhances

\section{Received Oct. 4, 2012; revised Dec. 28, 2012; accepted Jan. 9, 2013.}

Author contributions: H.A.P., A.S.H., L.S., J.L., and V.L.A. designed research; H.A.P., A.S.H., V.A., L.S., and V.L.A. performed research; H.A.P., A.S.H., V.A., L.S., J.L., and V.L.A. analyzed data; H.A.P., A.S.H., J.L., and V.L.A. wrote the paper.

This work was supported by grants from the Merit Review program of the Department of Veterans Affairs, the Department of Defense, and from the New York State Spinal Cord Injury Research Board.

The authors declare no competing financial interests.

Correspondence should be addressed to Dr. Victor L. Arvanian, Northport Veterans Affairs Medical Center, 79 Middleville Road, Bld. 62, Northport, NY 11768. E-mail: victor.arvanian@stonybrook.edu.

DOI:10.1523/JNEUROSCI.4702-12.2013

Copyright $\odot 2013$ the authors $\quad 0270-6474 / 13 / 334032-12 \$ 15.00 / 0$ axonal sprouting and regeneration in the damaged CNS (Moon et al., 2001; Bradbury et al., 2002; Caggiano et al., 2005; Tom et al., 2009; Alilain et al., 2011; García-Alías et al., 2011).

We have recently detected a novel function of CSPGs as modulators of axonal conduction. After a lateral hemisection (HX) injury, transmission through unlesioned axons contralateral to the HX injury is dramatically impaired during the chronic stage of injury (Arvanian et al., 2009). The initiation of these physiological deficits coincides with the time of maximal CSPG elevation in the tissue surrounding the HX injury (García-Alías et al., 2011) and treatment with Ch-ABC improves axonal conduction through these surviving axons in HX-injured rats (Hunanyan et al., 2010). Because Ch-ABC can remove the glycosaminoglycan chains from many different species of CSPGs, the identity of the specific CSPGs involved in modulating neurotransmission is unknown. In our search for individual CSPGs responsible for the block of axonal conduction in damaged spinal cord, we found that intraspinal injections of NG2 induced an acute potent block of axonal conduction, but similar intraspinal injections of aggrecan or neurocan did not have this effect (Hunanyan et al., 2010).

Recently, monoclonal antibodies have been developed that specifically neutralize the inhibitory properties of the NG2 proteoglycan. Application of these antibodies prevent NG2-induced block of axonal growth in vitro (Ughrin et al., 2003) and induce axonal regrowth into the nonpermissive environment of the glial 
scar in vivo (Tan et al., 2006). Here, we examined whether intraspinal injections of anti-NG2 monoclonal antibodies (NG2Abs) may prevent the acute block of axonal conduction induced by intraspinal injections of NG2. We also asked whether chronic administration of NG2-Ab via an osmotic minipump may improve axonal conduction, anatomical plasticity, and locomotor function after chronic HX injury. Some of these results have been reported in abstract form (Schnell et al., 2011a).

\section{Materials and Methods}

Design of experiments and experimental groups

All procedures were performed on adult, female Sprague Dawley rats $(\sim 210 \mathrm{~g})$ in compliance with Institutional Animal Care and Use Committee policies at State University of New York at Stony Brook and the Northport Veterans Affairs Medical Center. Four groups of rats were used in chronic experiments for behavior, electrophysiology, and anatomical tracing. Animals in the noninjured group received sham laminectomy and no treatments or injuries; the HX-only group received HX injury at the T10 level and no treatments; the NG2-Ab group received HX injury at T10 followed immediately by surgical implantation of an osmotic minipump to deliver an NG2-Ab mixture of two functionblocking antibodies, 69 and 147 [mouse monoclonal antibodies (Tan et al., 2006)]; and the control-Ab group received HX injury at T10 and delivery of control NG2 non-neutralizing 132 antibody immediately after surgery via implanted osmotic minipumps. After SCI and pump implantation, animals were evaluated for locomotor recovery for 8 weeks, after which electrophysiological or tracing experiments were performed. An additional six noninjured animals were used for acute electrophysiological experiments. Production, derivation, and specificity of two monoclonal NG2-function-neutralizing antibodies, designated as 69 and 147, and control NG2-function-non-neutralizing antibody 132 used in the current study have been described previously (Ughrin et al., 2003; Tan et al., 2006).

\section{SCIs and treatment delivery}

Animals were deeply anesthetized with $3 \%$ isoflurane in $100 \% \mathrm{O}_{2}$, then transferred to a face mask delivering $1.5 \%$ isoflurane in $100 \% \mathrm{O}_{2}$ to maintain anesthesia. A water-circulating heating pad was used to maintain body temperature during surgeries. Dorsal laminectomy was performed to expose T10 spinal cord level. A tip of an iridectomy scissor was inserted through the midline from dorsal to ventral and the left hemicord was completely transected as previously described (Arvanian et al., 2009).

Intrathecal administration of NG2 neutralizing antibody or control (non-neutralizing) antibody was given as previously described (Weinmann et al., 2006; Schnell et al., 2011b). Briefly, a fine intrathecal catheter was inserted from lumbar L2 and pushed to T10 to deliver a total volume of $2 \mathrm{ml}$ (concentration, $500 \mu \mathrm{g} / \mathrm{ml}$ for each antibody) of antibody from an osmotic minipump (Alzet 2ML2; $5 \mu \mathrm{l} / \mathrm{h}$ ) over 2 weeks. The minipump, placed subcutaneously, was connected to the intrathecal catheter via tubing sutured to the back muscles for stabilization. Antibody treatment was begun immediately after the lesion by rinsing the wound with $1 \mu \mathrm{l}$ of the corresponding antibody using a Hamilton syringe. The muscles were sutured in layers and skin closed with surgical clips, followed by subcutaneous injections of antibiotic (Baytril, $5 \mathrm{mg} /$ $\mathrm{kg}$ ), analgesic (buprenorphine, $0.01 \mathrm{mg} / \mathrm{kg}$ ), and $5 \mathrm{ml}$ of sterile lactated Ringer's solution.

Multiple studies, using a similar delivery technique, have revealed excellent distribution and penetration of antibodies infused intrathecally throughout the spinal cord of adult rats and monkeys (Weinmann et al., 2006) and is currently used in clinical trials to deliver Nogo-A antibody to human spinal cord. The presence of infused NG2-Ab bound to cells expressing NG2 within the lesion penumbra in adult rat spinal cord has been previously confirmed (Tan et al., 2006).

Reconstruction of the injury epicenter in all animals demonstrated that the mean lesion size was virtually identical for all groups (see Fig. 5). Five animals with underhemisection or overhemisection were removed from study (in addition to 4 animals excluded $2 \mathrm{~d}$ postinjury based on open-field performance) (see below).

\section{Behavioral assessment}

Open-field Basso-Beattie-Bresnahan score. Before injury, but following an acclimation and handling period, locomotor behavior was evaluated with open-field Basso-Beattie-Bresnahan (BBB) score (Basso et al., 1995). Two days after surgery, animals were scored with BBB test to assess severity of injury. Four animals with less impairment than is typical for lateral HX SCI at this time point (Arvanian et al., 2009; Schnell et al., 2011b) were eliminated from the study. Rats were observed in an open field and BBB testing was performed by two independent observers for 4 min. Joint movements, weight support, paw placement, and coordination were evaluated according to the 21-point BBB locomotion scale.

CatWalk gait analysis. Animals were pretrained to cross a special glass runway, where their footprints were captured by a high-speed camcorder. Quantitative assessment of footprints and analyses were done using CatWalk XT software (Hamers et al., 2001) (CatWalk, Noldus Information Technology) beginning at 2 weeks postoperation (i.e., time point when animals exhibited weight-supported stepping). Data from three complete runs for each animal were collected and gait parameters, such as stride length and base of support, objective measurements of locomotor deficits after lateral HX injury (García-Alías et al., 2011), were compared between experimental groups.

\section{Electrophysiological evaluation}

Animals were deeply anesthetized using a ketamine/xylazine mixture (80 $\mathrm{mg} / \mathrm{kg} / 10 \mathrm{mg} / \mathrm{kg}$ ) injected intraperitoneally for induction and supplemented during experiment with one-fifth initial dose injected intramuscularly if needed. Expired $\mathrm{CO}_{2}$ and heart rate were continuously monitored. An automatically controlled heating pad was used to maintain animal body temperature at $36.7^{\circ} \mathrm{C}$. Dorsal laminectomies were performed at T5-T7 (for placement of stimulation electrode rostral to HX injury) and L1-L6 (for placement of recording and stimulation electrodes at L1 caudal to HX injury).

Intracellular responses (Axoprobe amplifier, Molecular Devices) were recorded from L5 motoneurons and evoked by electric stimulation of ventrolateral funiculus (VLF) at T6 rostral or at L1 caudal to HX injury as described previously (Arvanian et al., 2009; Hunanyan et al., 2012). Briefly, motoneurons were impaled with sharp, glass microelectrodes (3 $\mathrm{M} \mathrm{K}$-acetate; 50-70 $\mathrm{M} \Omega$ resistance) and identified by their antidromic response to stimulation of the cut L5 ventral root.

Intra-axonal recordings (Axoprobe amplifier; Molecular Devices) were performed from lateral white-matter axons at L1 level [from dorsal surface to a depth of $\sim 2 \mathrm{~mm}$ (i.e., corresponding to VLF)] using sharp, glass microelectrodes with resistances of 25-50 M , filled with $3 \mathrm{M}$ K-acetate, as previously described (Hunanyan et al., 2011). Briefly, axons were identified by drop of membrane potential, no changes of action potential (AP) amplitude when the stimulus intensity was changed above threshold to evoke a response, and no underlying synaptic potential (Kocsis and Waxman, 1980). Axons with membrane potentials more negative than $\sim 55 \mathrm{mV}$ were used for analysis. We used an active bridge circuit that allowed simultaneous recording and current injection through the same electrode.

Extra-axonal recordings were performed as previously described (Hunanyan et al., 2011). Extracellular responses were acquired from L1 lateral white matter at a depth corresponding to VLF using a tungsten electrode (resistance, $300 \mathrm{k} \Omega$; FHC). The electrode was positioned at an angle of $20-22^{\circ}$ to enter the lateral white matter of the cord from vertical in the sagittal plane (Hunanyan et al., 2012). Extracellular composed AP volley responses were recorded and 50 consecutive responses were averaged.

For electrical stimulation (using Pulsmaster A300/Stimulus Isolator A360, World Precision Instruments), a tungsten electrode (resistance, $300 \mathrm{k} \Omega$; FHC) was placed in T6 or L1 lateral white matter to recruit fibers located in the VLF. Stimulation electrode was positioned between the dorsal root entry zone and lateral edge at $25^{\circ}$ angle via micromanipulator and lowered to the depth of $1.7 \mathrm{~mm}$ for T6 and $2 \mathrm{~mm}$ for L1 stimulation as previously described (Arvanian et al., 2009; Hunanyan et al., 2011).

Motoneurons used for analysis had a resting membrane potential that ranged from -45 to $-65 \mathrm{mV}$. The maximum synaptic response for each cell was determined as previously described (Arvanian et al., 2009; 
Hunanyan et al., 2012). Peak EPSP amplitude was calculated from the prestimulus baseline to the peak amplitude. All signals were digitized at $100 \mathrm{kHz}$, stored on a PC, and analyzed off-line using PClamp 10 software. We usually recorded 7-8 motoneurons or axons per rat. The peak amplitude of EPSPs from all motoneurons (30 consecutive responses per cell) were averaged over all motoneurons recorded in each rat and compared using one-way ANOVA on ranks ( $n$, number of rats).

\section{Intraspinal injections of NG2 and NG2-Ab during terminal} electrophysiological recording

To examine acute effects of NG2 antibody and NG2 on synaptic transmission, intact rats were anesthetized as described above and a laminectomy was performed to expose T6 (for placement of stimulation electrode), T10 (for placement of injection capillary), and L1-L6 (for placement of recording electrode) spinal cord. A custom-made twobarrel pipette was fabricated by gluing together two separately pulled glass pipettes, $20 \mu \mathrm{m}$ diameter each, at an angle of $\sim 20^{\circ}$ so that the tips were within $10 \mu \mathrm{m}$ of each other. One tip was filled with NG2-Ab and the other tip was filled with NG2. The tip of this two-barrel pipette was positioned in the T10 lateral white matter of the spinal cord using a micromanipulator to ensure that the injections were made in the vicinity of axons being stimulated: the position and depth of the tip of the injecting pipette (at T10) were determined by adding $100 \mu \mathrm{m}$ to the position and depth of the stimulating electrode (at T6) (to account for the greater thickness of the cord in T10).

\section{Retrograde tracing, tissue processing, and cell counting}

After completion of behavioral testing, animals from groups dedicated for retrograde axonal tracing experiments were anesthetized with isoflurane as described above. Fluororuby (FR; 10,000 molecular weight; Fluorochrome), $10 \%$ in distilled $\mathrm{H}_{2} \mathrm{O}(\sim 1.5 \mu \mathrm{l}$ of total volume), was injected into L5 gray matter ipsilateral to HX injury (3 injections at 2, 1.5, and $1 \mathrm{~mm}$ from dorsal surface of the cord) with a glass micropipette (20 $\mu \mathrm{m}$ diameter) attached to a Hamilton syringe and a micromanipulator. Injection was performed over $5 \mathrm{~min}$ to maximize uptake and minimize spilling of the tracer. Muscles and skin were closed and analgesics and antibiotics were administered as described above.

Following a survival time of 2 weeks post-FR injections, rats were given an overdose of urethane and, when completely unresponsive to nociceptive stimuli, were perfused transcardially with $100-200 \mathrm{ml}$ of $0.1 \mathrm{M}$ PBS containing $0.6 \%$ heparin followed by $400 \mathrm{ml}$ of $4 \%$ paraformaldehyde in $0.1 \mathrm{M}$ PBS. Spinal cords were removed and postfixed for $1-2 \mathrm{~h}$ in the perfusion mixture described above, then rinsed with $0.1 \mathrm{M}$ PBS overnight, and infused with $30 \%$ sucrose in $0.1 \mathrm{M}$ PBS for several days for cryoprotection. Spinal cord segments of interest were sectioned on a cryostat at $40 \mu \mathrm{m}$ in the transverse plane and collected onto Colorfrost Plus slides (Thermo Fisher Scientific). Serial order was maintained over five sets of slides. Cresyl violet was used to stain one complete set of serial sections (each section separated by $200 \mu \mathrm{m}$ ) for use in determining spinal cord segment level and for injury reconstruction as previously described (Liebscher et al., 2005; Arvanian et al., 2006). To visualize FR labeling, an adjacent serial set was air-dried overnight, rinsed in $0.1 \mathrm{M}$ PBS to remove embedding medium (Neg 50, Richard-Allan Scientific), dried on a slide warmer at $50^{\circ} \mathrm{C}$ for half an hour, and then cleared with xylene and coverslipped with DPX.

Sections were analyzed under a Zeiss Axioskop2 equipped with fluorescent capability or a confocal Olympus Fluoview FV1000 microscope. Images were captured with an AxioCam MRm camera (Carl Zeiss) and analyzed with AxioVision Rel 4.8 software. FR-labeled cells were counted in the L1-L2 and T4-T7 segments (corresponding to the position of stimulating electrodes in electrophysiological experiments).

\section{Immunohistochemistry and image analysis}

After completion of electrophysiological experiments, animals were given an overdose of urethane and transcardially perfused. Then spinal cords were removed and postfixed as above. The T9-T11 spinal segments were prepared for cryostat sectioning and five sets of $20-\mu \mathrm{m}$-thick longitudinal sections were collected onto slides. One set was stained with cresyl violet for injury reconstruction (details in Hunanyan et al., 2010) and other sets were used for further immunostaining.
Double immunofluorescence staining for CASPR/NG2 and CASPR/Na ${ }^{+}$ channel and confocal microscopy to evaluate distribution of NG2 in regard to location of $\mathrm{Na}^{+}$channels within nodal gap. For immunofluorescence staining with Caspr $/ \mathrm{Na}^{+}$channels and Caspr/NG2, the alternating sections were blocked for $1 \mathrm{~h}$ in $6 \%$ normal goat serum in PBS containing $0.3 \%$ Triton X-100 and then incubated in appropriate primary antibodies: mouse anti-Caspr (1:1000; NeuroMab; in case of double staining for NG2) and rabbit anti-NG2 (1:500; Millipore), or rabbit anti-Caspr (1: 500; Santa Cruz Biotechnology; in case of double staining for $\mathrm{Na}^{+}$channels) and mouse anti-Na ${ }^{+}$channel-pan antibody [1:1000 SigmaAldrich; found to recognize the major types of $\mathrm{Na}^{+}$channel that cluster at essentially all nodes of Ranvier (Feinberg et al., 2010)] overnight in $4^{\circ} \mathrm{C}$. Sections then washed with PBS $(3 \times 10 \mathrm{~min})$ and incubated in secondary Alexa Fluor (Invitrogen), goat-anti-rabbit and goat-antimouse secondary antibodies at a 1:1000 dilution for $1 \mathrm{~h}$ at room temperature. After incubation in secondary antibodies, the sections were washed in PBS, rinsed in distilled $\mathrm{H}_{2} \mathrm{O}$ and coverslipped with Fluoromount-G (Southern Biotech). $Z$-stack images from double-stained sections were taken with a Zeiss LSM 510 confocal microscope. We used Caspr/NG2labeled sections to qualitatively evaluate and quantify number of nodes contacting NG2-positive processes within the fixed area at the lateral edge of the T10 segment across the HX injury at the depth of $\sim 1.7 \mathrm{~mm}$ (dorsal to ventral) from five sections per animal in each group.

Immunostaining for 5-HT-positive fibers. For immunofluorescence staining with 5-HT, we used transverse sections from the FR experiment (see above). The primary antibody used was rabbit anti-5-HT (1:1000, ImmunoStar) followed by the incubation with secondary antibody goat anti-rabbit Alexa Fluor 488 (1:200, procedures described above). All images were adjusted to eliminate background and account for 5-HTpositive $(5-\mathrm{HT}+)$ profiles. We quantified immunoreactivity of $5-\mathrm{HT}+$ fibers at L1-L5 segments and calculated the thresholded pixel mean intensity and threshold pixel area for images taken with the same exposure settings (Tom et al., 2009) with Olympus Fluoview FV1000 confocal microscope using both TRITC and FITC filters within a fixed area of ventral horn.

\section{Statistical analysis}

Statistical analyses for electrophysiology, tracing, and behavioral experiments were performed using SigmaPlot 11.0 software (Systat Software). A one-way ANOVA on ranks followed by Tukey's multiple-comparisons post hoc test was used to compare the groups. Data are means \pm SE. $p<$ 0.05 was considered statistically significant.

\section{Results}

Intraspinal injection of NG2-Ab acutely prevents the block of axonal conduction induced by acute NG2 administration

In a previous study, we found that intraspinal injections of purified NG2 in the vicinity of axons in lateral white matter of noninjured animals depressed transmission to L5 motoneurons through these axons (Hunanyan et al., 2010). In the current study, we examined the ability of the acute administration of $\mathrm{NG} 2-\mathrm{Ab}$ to prevent these inhibitory effects in the intact spinal cord. A two-tip micropipette, one tip filled with NG2-Ab and the other with NG2, was positioned in lateral white matter between the recording and stimulating electrodes (Fig. 1). After measuring the control intracellular responses evoked by electric stimulation of lateral white matter at T6, the NG2-Ab ( $1 \mu \mathrm{l})$ was slowly injected from one barrel and responses were measured again. Thirty minutes following NG2-Ab injection, purified NG2 (Ughrin et al., 2003) was injected from the other barrel and responses were measured again. We found that intraspinal injections of NG2-Ab did not induce changes in the amplitude of intracellularly recorded EPSPs, but prevented the block of EPSPs by subsequent NG2 injection. Amplitude of control intracellular responses was $5.6 \pm 0.8 \mathrm{mV}$; amplitude of intracellular responses after $30 \mathrm{~min}$ of $\mathrm{Ab}$ injections was $5.7 \pm 0.9 \mathrm{mV}$; and amplitude of intracellular responses after 30 min of NG2 injection (following 


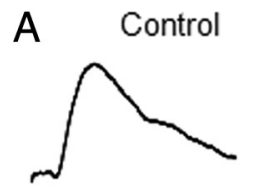

B

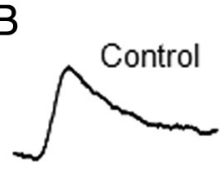

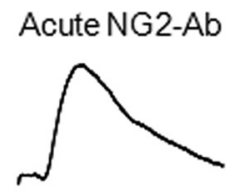

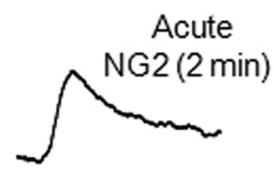

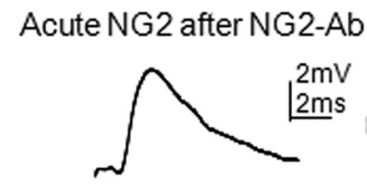
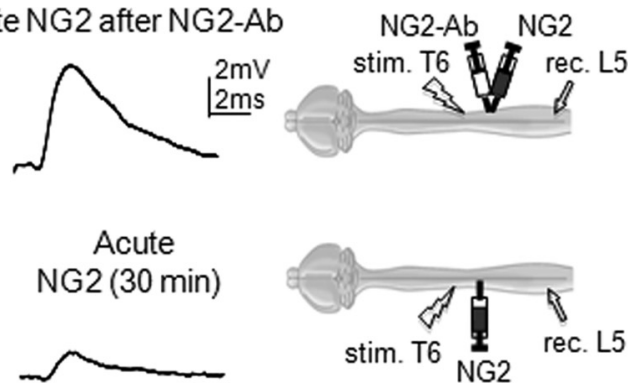

Figure 1. Intracellular recordings demonstrating acute effects of NG2 antibody on removing inhibitory effect of NG2 on axonal conduction. Representative traces of EPSPs recorded intracellularly from L5 motoneurons and evoked by stimulation of T6 ventrolateral funiculus in same noninjured adult rat, before and after intraspinal injections of NG2-Ab or NG2. Diagrams show positions of stimulation (stim.) electrode in T6, recording (rec.) electrode in $L 5$ and injection micropipette at T10. $A$, Superimposed averaged responses showing absence of inhibitory effect of NG2 on conduction in presence of NG2-Ab; control (before injection), 30 min after injection of NG2-Ab, and 30 min after injection of NG2, which was injected 30 min after NG2-Ab injection, respectively. $\boldsymbol{B}$, Superimposed averaged responses recorded from the opposite side of the cord in same rat, showing depression of EPSPs after injection of NG2 in absence of NG2-Ab; control (before injection), 2 min after injection of NG2, and 30 min after injection of NG2, respectively.

Ab injection) was $5.5 \pm 0.6 \mathrm{mV}(p>0.05, n=6$ rats, $7-8$ cells/rat). After completion of these injections and recordings on one side of the spinal cord, the stimulating and recording electrodes were removed and positioned symmetrically in the opposite side of the cord and the recordings were performed following injections of NG2 only. A micropipette containing NG2 was positioned between the stimulating and recording electrodes $5 \mathrm{~mm}$ caudal off the position of the initial injection at the opposite side of the cord. Under these conditions, intraspinal injections of NG2 induced a depression of the responses recorded intracellularly from L5 motoneurons. NG2-induced depression versus control responses was $72 \pm 7 \%(p<0.05, n=6)$. Consistent with the effects of intraspinal injections of NG2 alone in a previous study (Hunanyan et al., 2010), intraspinal injections of NG2 did not induce immediate changes in the shape of EPSPs, but depressed EPSP amplitude 20-25 min postinjection. These results show that the acute administration of NG2-Ab prevents the blockade of axonal conduction induced by acute NG2. Moreover, these results demonstrate that the approach of administering NG2-Ab via intraspinal injections blocked the acute inhibitory effects of $\mathrm{NG} 2$ on axonal conduction only in the vicinity of the intraspinal injections. This suggests the possibility that intraspinal injections of the NG2-Ab may be useful for local neutralization of NG2 in the areas where needed, such as the site of SCI.

\section{Chronic infusion of NG2-Ab improves synaptic plasticity in damaged spinal cord}

Using a clinically relevant intrathecal delivery method, we next examined whether chronic treatment with NG2-Ab improves transmission after a chronic HX SCI. In this study, NG2-Ab was delivered to the vicinity of HX lesion via osmotic minipump chronically for 2 weeks, which corresponds to the time point when accumulation of CSPGs around the HX injury reaches its maximum level (García-Alías et al., 2011). Rats received HX injury and immediately after the HX injury were implanted with a subdural catheter delivering either NG2-Ab or control-Ab from osmotic minipumps for 2 weeks. Eight weeks after surgery and behavioral testing, we recorded intracellularly from L5 motoneurons the responses evoked by electric stimulation of lateral white matter at T6 (i.e., rostral to T10 HX injury) and L1 (i.e., caudal to HX-injury level). We found that in animals that received HX injury and chronic treatment with a control-Ab, responses of L5 motoneurons evoked from both T6 and L1 levels were depressed significantly compared with noninjured animals. The mean amplitude of these diminished responses was $0.8 \pm 0.5 \mathrm{mV}$ from $\mathrm{T} 6$ and $2.1 \pm 0.4 \mathrm{mV}$ from L1 (Fig. $2, n=5$ rats, 37 cells total) (i.e., similar to the amplitude of corresponding responses in animals that received a HX SCI and no treatment in previous study) ( $~ 0.9 \mathrm{mV}$ from T6 and $\sim 2.5 \mathrm{mV}$ from L1; Arvanian et al., 2009). In animals treated with NG2 function-blocking antibody, the amplitude of the responses from T6 increased significantly ( $1.58 \pm 0.38 \mathrm{mV}, n=7, p<0.05$; Fig. 2) compared with controlAb-treated animals or HX no treatment (Arvanian et al., 2009). The amplitude of responses from L1 was significantly higher as well (3.8 $\pm 0.6 \mathrm{mV}, n=7, p<0.05$; Fig. 2) compared with HX no-treatment animals (Arvanian et al., 2009) or animals from the control-Ab-treated group (Fig. 2E). These results suggest that chronic treatment with NG2-Ab may improve transmission to L5 motoneurons through VLF fibers from rostral and caudal to injury epicenter spinal segments after HX SCI.

\section{Cellular and molecular mechanisms underlying effects of NG2-Ab on transmission deficits in chronically damaged spinal cord}

How does NG2-Ab treatment increase transmission through VLF fibers? To examine possible effects of NG2-Ab on the physiological functions of the spared axons, we conducted extracellular recording and intra-axonal recordings from individual axons in L1 white matter in NG2-Ab-treated and control-Ab-treated animals as previously described (Hunanyan et al., 2011) (note that these intra-axonal recordings were taken at a position corresponding to the position of one of the stimulation electrodes described in Fig. 2). Amplitude of volley responses is known as an excellent marker of axonal conduction (Lloyd, 1949).

Effects of NG2-Ab on axonal conduction. Recordings of extracellular volley responses from L1 lateral white matter in response to stimulation of VLF axons at T6 (rostral to HX injury) in chronic HX-injury rats showed that the peak amplitude of the volley responses in control-Ab group was diminished significantly $(0.11 \pm 0.01 \mathrm{mV}, n=6$ rats, $p<0.05)$, compared with previously reported measures in noninjured rats $(\sim 0.3 \mathrm{mV}$; Hunanyan et al., 2011). Consistent with NG2-Ab-induced facilitation of synaptic responses (Fig. 2), chronic HX-injury and NG2-Ab-treated animals exhibited a significantly larger amplitude of the volley responses $(0.19 \pm 0.02 \mathrm{mV}, n=7$ rats, $p<0.05)$ compared with HX/control-Ab group (Fig. $3 A$ ). These results suggest that NG2-Ab treatment may improve conduction deficits in spared axons spanning the injury epicenter after chronic HX SCI. However, this extracellular method cannot provide sufficient information about whether the changes in axonal conduc- 
tion are due to the effects of the neutralizing NG2-Ab on the axonal membrane potential, input resistance, or excitability.

Effects of NG2-Ab on axonal excitability. To test any possible effect of NG2-Ab on the physiological function of the spared axons, we conducted intra-axonal recordings from individual axons in $\mathrm{L} 1$ white matter in NG2-Ab-treated and control-Ab-treated animals as described previously (Hunanyan et al., 2011). Intraaxonal recordings provide precise information about excitability of these axons (Kocsis and Waxman, 1982; Blight, 1983). These intra-axonal recordings were conducted in the L1 segment; stable recordings from axons at thoracic level were not possible because immobilization of the thoracic cord interfered with breathing. For each recorded axon, we measured membrane potential and examined membrane properties by applying both hyperpolarizing and depolarizing current steps through the recording electrode (Fig. $3 B$ ). By applying hyperpolarizing steps, we determined axonal input resistance, and by applying depolarizing steps, we determined the rheobase of axons (the minimum depolarization current required to trigger APs), a marker of axonal excitability. Reported rheobase was $\sim 0.4 \mathrm{nA}$ in noninjured and $\sim 0.8 \mathrm{nA}$ in chronically HX-injured animals (Hunanyan et al., 2011). We found that chronic treatment with NG2-Ab significantly decreased rheobase (i.e., increased excitability) of axons compared with control-Ab-treated animals (NG2-Ab: $0.5 \pm 0.1 \mathrm{nA}, n=7 \mathrm{rats} / 34$ axons; control-Ab: $0.9 \pm 0.1 \mathrm{nA}, n=$ 6 rats/29 axons; $p<0.05$; Fig. $3 B$ ). The mean input resistance of the axons acquired through hyperpolarizing current pulses was not significantly different in both groups (NG2-Ab, $79 \pm 7.2$ $\mathrm{M} \Omega$; control-Ab, $81 \pm 7.6 \mathrm{M} \Omega ; p>0.05)$. The results suggest that chronic treatment with NG2-Ab partially overcomes the diminished physiological state of individual spared axons by increasing the excitability of these axons after chronic HX injury.

Immunostaining for nodes of Ranvier, nodal $\mathrm{Na}^{+}$channels, and NG2 in white matter contralateral to HX injury

The processes of NG2-expressing cells contact nodes of Ranvier (Butt et al., 1999) and exogenous NG2 accumulates along axons and at nodes of Ranvier in intact white matter (Hunanyan et al., 2010). Because nodes of Ranvier are critical for axonal excitability and the propagation of action potentials along axons (Waxman and Ritchie, 1993), we examined whether changes in excitability of spared axons revealed by electrophysiological experiments above were associated with changes in the presence of NG2 in the vicinity of $\mathrm{Na}^{+}$channels.

To visualize the distribution of NG2-positive processes in relation to nodal $\mathrm{Na}^{+}$channels, we used double staining with Caspr/NG2 and Caspr/ $\mathrm{Na}^{+}$channels (Pan-Na). Double immunostaining with Pan-Na and Caspr revealed clusters of $\mathrm{Na}^{+}$ channels in virtually all nodes of Ranvier between Caspr-labeled nodal doublets (Fig. 4A). Examination of sequence of individual confocal $Z$-slices suggests that $\mathrm{Na}^{+}$channels cluster within the nodal gap in spared VLF axons contralateral to chronic HXinjury white matter as they do in injured control animals (Fig. $4 D$ ). Double immunostaining with NG2 and Caspr revealed the NG2-positive processes (probably of oligodendrocyte progenitor cells) contralateral to HX-injury white matter. Many of these NG2-positive processes appeared to be in close contact with nodes of Ranvier (Fig. 4B). The examination of individual confocal $Z$-slices (Fig. $4 E$ ) suggests location of NG2-positive processes within the nodal gap, corresponding to the location of nodal $\mathrm{Na}^{+}$channels in alternating sections. Note that because the infused NG2-Ab was monoclonal mouse antibody (Tan et al., 2006), immunostaining of NG2 using secondary antirabbit antibody shown in Figure 4 would detect only primary rabbit anti-NG2 antibody used for NG2 staining, but not the infused NG2-Ab.

Comparison of sections double stained for Caspr and NG2 from injured and noninjured cords revealed a significantly higher number of nodes with close contacts with NG2-positive processes in injured animals (Fig. 4F). These results suggest that a possible interaction of NG2 with $\mathrm{Na}^{+}$channels within the nodal gap may underlie the blocking effects of NG2 on the physiological properties of spared axons during the chronic stage of HX SCI. Qualitative comparison of sections from NG2-Ab and control$\mathrm{Ab}$-treated animals revealed a trend for decrease in the number of 
A
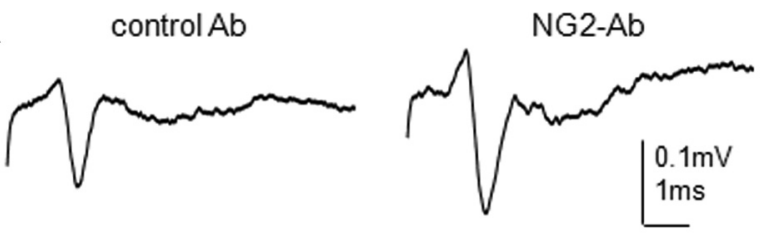

B
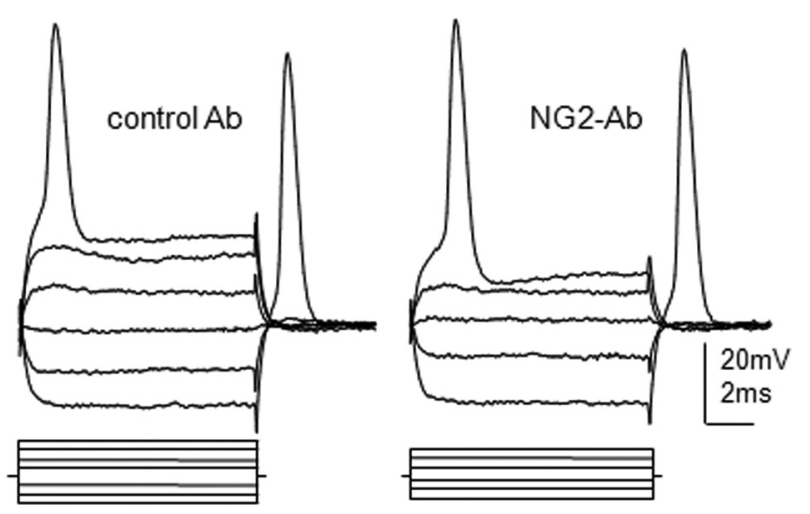

Figure 3. Intra-axonal and extra-axonal recordings from lateral white-matter axons to demonstrate effect of NG2-Ab treatment on physiological properties of axons. $A$, Extracellular recordings of AP volley responses to demonstrate improved conduction in NG2-Ab-treated animal. Representative traces of the volley of APs recorded extracellularly from ventrolateral funiculi at L1 segment and evoked by electric stimulation of VLF at T6 contralateral to HX injury in NG2-Ab-treated and control-Ab-treated chronic HX-injured rats. $\boldsymbol{B}$, Intra-axonal recordings from L1 VLF axons. Representative traces recorded from single axons in control-Ab-treated and $\mathrm{NG2}$-Ab-treated animals, respectively. Both axons had a resting membrane potential of $\sim 60$ $\mathrm{mV}$. Current steps (displayed below the voltage traces) of a $0.2 \mathrm{nA}$ increment were applied through the recording electrode in both hyperpolarizing (to measure membrane resistance) and depolarizing directions (to trigger an AP). Note the higher rheobase but similar membrane resistance in the axon from control-Ab-treated spinal cord.

nodes contacting NG2-positive processes in NG2-Ab-treated animals. However, NG2-Ab and control-Ab groups did not show statistically significant quantitative differences in the paranodal distribution of $\mathrm{Na}^{+}$channels and NG2 between these two animal groups (Fig. $4, p=0.47$ ). Thus, it seems that the observed increase in electrical excitability in the NG2-Ab-treated cases is not due to a change in the distribution of NG2 + process at nodes of Ranvier. We cannot rule out change in nodal ultrastructure, however, and further electronmicroscopy studies must be conducted to understand possible mechanisms underlying effects of NG2-Ab on axonal conduction.

In a control experiment, to examine whether the infused NG2-Ab was still present at the nodes after 6 weeks following removal of the minipumps, we stained the alternating sections with secondary Alexa-Fluor 488 anti-mouse antibody without the primary antibody. There was no detectable signal (data not shown). These results are consistent with previous observation (Tan et al., 2006) that showed that the infused antibody bound to the NG2-positive cells in the injured spinal cord at $3 \mathrm{~d}$ postinfusion was not detectable after 2 weeks postinjury survival times. Thus these results demonstrate that functional effects of NG2-Ab on axonal conduction last beyond the time of infusion of NG2-Ab.

\section{Neutralization of NG2 by NG2-Ab improves anatomical plasticity \\ FR retrograde transport}

To study whether the beneficial effects of NG2-Ab on synaptic transmission may be associated with improved anatomical plasticity, we used the retrograde axonal transport of FR to examine intraspinal connectivity rostral and caudal to the lesion site. In an attempt to label interneurons whose somata are in thoracic (T4T7) and high lumbar (L1-L2) segments and whose axons extend to the L5 motor neurons, we conducted the following tracing experiments. Eight weeks after injury, FR was injected into L5 gray matter ipsilateral to HX injury at the level corresponding to the position of the recording electrode in electrophysiological experiments. Two weeks after FR injections, we assessed the distribution of labeled cells in lumbar (L1-L2 segments, caudal to HX injury) and thoracic (T4-T7 segments, rostral to HX injury) gray matter, at the levels corresponding to the position of stimulation electrodes in lateral white matter in electrophysiological experiments. As in the electrophysiological experiments, we used four animal groups: (1) noninjured $(n=5),(2)$ HX injury with no treatment $(n=5),(3)$ HX injury and control-Ab $(n=6)$, and (4) HX injury and NG2-Ab $(n=6)$.

In noninjured animals, we found many tracer-filled neurons in lumbar L1-L2 segments; fewer, but still many neurons were retrogradely traced in T4-T7 segment (Fig. 5A). These FRlabeled neurons are most probably commissural propriospinal neurons projecting from upper (T4-T7 and L1-L2) spinal segments to lower (L4-L5) segments through VLF, as previously suggested (Conta and Stelzner, 2004; Reed et al., 2006, 2009). There was a dramatic reduction in the number of labeled cells in both L1-L2 and T4-T7 spinal segments of injured animals compared with noninjured control animals (Fig. 5). The total mean number of labeled cells in L1-L2 segments was $325 \pm 13$ in noninjured versus $106 \pm 15$ in HX-injured rats $(p<0.05)$. In thoracic T4-T7 level, the number of FR-filled cells was $32 \pm 2$ in noninjured controls and only a few cells $(2 \pm 0.7)$ were retrogradely labeled in HX-injured rats $(p<0.05$, Fig. 5). In the HXinjured control-Ab group, the total number of FR-labeled cells at both L1-L2 (112 \pm 14$)$ and T4-T7 (2.6 \pm 1.2$)$ levels was also reduced dramatically compared with the noninjured cord and was not significantly different from the HX-only group. Importantly, the total number of FR-filled cells in L1-L2 segments of NG2-Ab-treated animals was significantly higher $(231 \pm 26)$ compared with both the HX nontreated $(\sim 106$ cells $)$ and control-Ab $(\sim 112$ cells) groups (Fig. $5 ; p<0.05)$. It should be noted, however, that the number of labeled cells in T4-T7 segments in the HX NG2-Ab group remained extremely low and it was not significantly different from the number in HX nontreated and HX-injured control-Ab-treated groups (Fig. 5). The mean measured area of the spared contralateral white matter at the injury epicenter in dorsal columns (NG2-Ab group, $0.19 \pm 0.04 \mathrm{~mm}^{2}$; control Ab group, $0.21 \pm 0.03 \mathrm{~mm}^{2}$; $p>0.05)$ and lateral columns (NG2-Ab group, $1.29 \pm 0.07$ $\mathrm{mm}^{2}$; control Ab group, $\left.1.35 \pm 0.06 \mathrm{~mm}^{2} ; p>0.05\right)$ was not significantly different.

These results suggest that neutralization of NG2 may either prevent cell death, partially preserve axonal connections between segments L1 and L5, or restore/maintain axonal transport in these nerve fibers. These anatomical results are in a good agreement with electrophysiological recordings (Fig. 2) demonstrating the enhanced synaptic plasticity in the L1-L5 segment of the injured spinal cord.

\section{5-HT immunoreactivity}

Most regenerating fibers in the injured spinal cord are serotonergic (Holmes et al., 2005; Kim et al., 2006; van den Brand et al., 2012), including those that sprout after treatment with Ch-ABC (Barritt et al., 2006; Tom et al., 2009; Alilain et al., 2011). Therefore, we stained sections with antibody against 5-HT to measure 
A

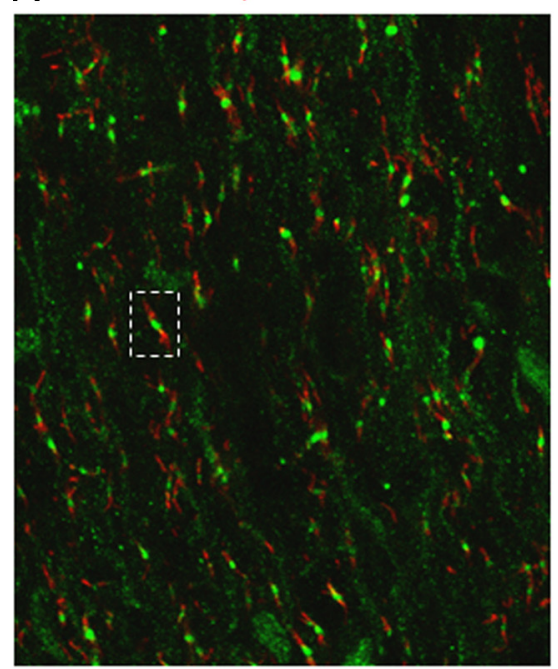

D Individual Z-slices: Caspr/Pan-Na

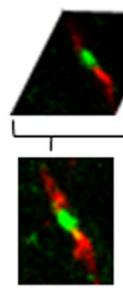

B

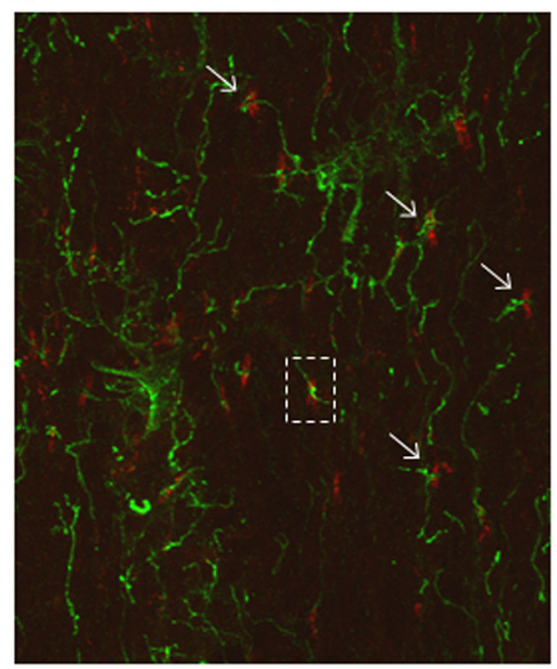

$\mathrm{E}$
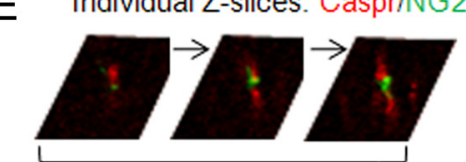

Collapsed Z-projection

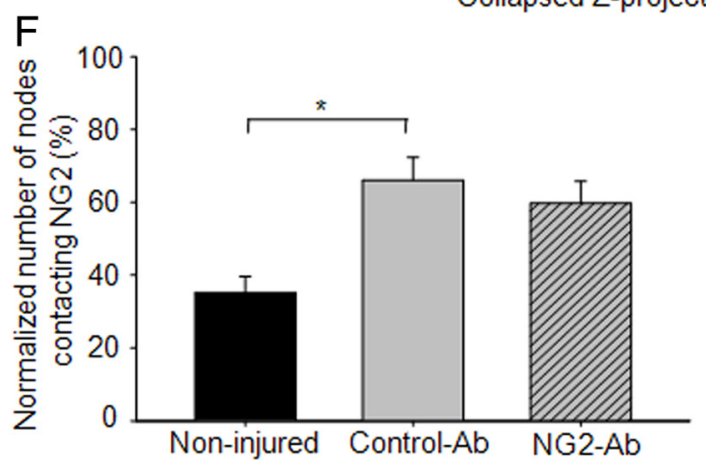

C
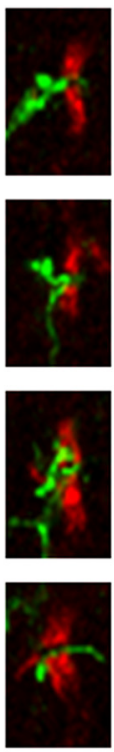

Caspr/NG2

Collapsed

Z-projections

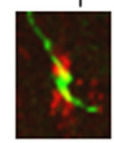

Figure 4. Confocal images of alternating longitudinal sections representing double immunostaining with Caspr/Pan-Na $(\boldsymbol{A})$ and Caspr/NG2 $(\boldsymbol{B})$ to show localization of $\mathrm{Na}{ }^{+}$channels and NG2-positive processes in relation to nodes of Ranvier in the lateral white matter across to chronic $\mathrm{HX}$ injury at depth corresponding to $\mathrm{VLF}$. $A, \mathrm{Na}^{+}$channel immunoreactivity was found within almost all nodes of Ranvier. $\boldsymbol{B}$, Many NG2-positive processes make close contacts with nodes of Ranvier. $\boldsymbol{C}$, High-power views show NG2-positive processes in close relation to nodal gap at nodes indicated by arrows in $\boldsymbol{B}$. $\boldsymbol{D}, \boldsymbol{E}$, Individual Z-slices separated by $1 \mu \mathrm{m}$ to show localization of $\mathrm{Na}^{+}$-channel clusters $(\boldsymbol{D})$ and NG2-positive processes $(\boldsymbol{E})$ within nodal gap highlighted in $\boldsymbol{A}$ and $\boldsymbol{B}$, respectively. $\boldsymbol{F}$, Summary of results demonstrating significantly higher number of nodes that make close contact with NG2-positive processes within nodal gap in injured versus noninjured animals. Asterisks represent significant difference between corresponding graphs $(p<0.05)$. Scale bar, $10 \mu \mathrm{m}$.

any effects of NG2-Ab treatment on sprouting and regeneration. As shown in Figure 5, there was significantly higher 5-HT immunoreactivity in ventral areas of L1-L5 segments in rats that received HX injury and NG2-Ab treatment versus the control-Ab group. These results suggest that treatment with NG2-Ab can result in enhanced density of fibers around neurons caudal to the lesion. Descending serotonergic inputs are known to be involved in locomotion function (Jordan et al., 2008), and recovery of 5-HT immunoreactivity in damaged spinal cords, particularly at lumbar levels, was shown to correlate with locomotor recovery following spinal cord injury in rats (Saruhashi et al., 1996; Kim et al., 2006; Jeong et al., 2011).

\section{Behavioral recovery}

To examine whether improvements of synaptic transmission and anatomical plasticity in spinal circuits induced by NG2-Ab correlate with better recovery of function, we have conducted a set of behavioral tests.

\section{$B B B$}

Consistent with previous reports (Hains et al., 2001; Ballermann and Fouad, 2006; Courtine et al., 2008; Arvanian et al., 2009), during the first 2 weeks posthemisection, animals showed partial recovery of locomotor functions, reaching a plateau after $\sim 3$ weeks. During recovery phase at weeks 2 and 3 postinjury, NG2Ab-treated rats showed significantly better $(p<0.05)$ recovery of locomotor function versus control-Ab-treated rats (Fig. 6). However, beginning at 4 weeks and continuing through week 8 , no significant differences were observed between groups in BBB locomotor score (Fig. 6). It is important to note that the quasiquantitative BBB scoring has been widely used for evaluating the loss of function and recovery following injury and is particularly useful for locomotor evaluation during the initial days postinjury, when other challenging tests cannot be performed because of lack of adequate locomotor function. However, the BBB protocol was not sensitive enough to assess the subtle improvements that result from treatments after thoracic HX injury in rodents because of 


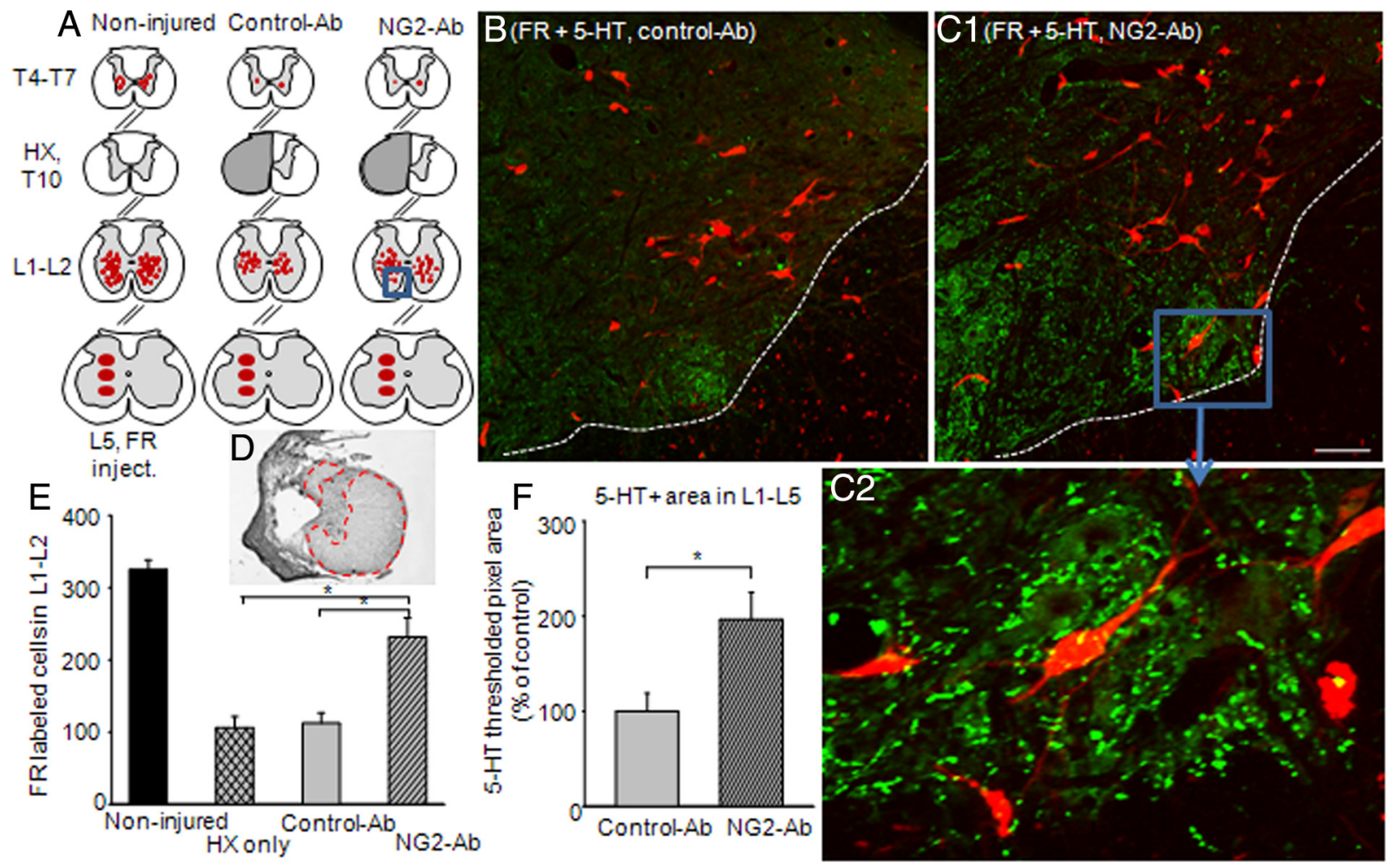

Figure 5. Chronic treatment with NG2-Ab improved retrograde transport of FR and density of 5-HT-positive fibers in lumbar segment of chronic HX-injured animals. A, Schematic representation of FR injection site at L5 gray matter and distribution of FR-labeled cells at L1-L2 and T4-T7 spinal segments in noninjured and HX-injured rats treated with NG2-Ab and control-Ab, respectively. $B, C$, Representative images of lumbar sections from FR experiment stained for 5-HT-positive (5-HT+) fibers of injured animals treated with control-Ab (B) or NG2-Ab (C1), respectively. Dotted lines in $\boldsymbol{B}$ and $\mathbf{C r e p r e s e n t ~ w h i t e ~ m a t t e r - ~ g r a y ~ m a t t e r ~ b o u n d a r y . ~ S c a l e ~ b a r , ~} 100 \mu \mathrm{m}$. C2, Higher-power image of boxed area in $\mathbf{C} 1$ to demonstrate high density of 5 -HT-positive fibers in lumbar ventral horn in the vicinity of neurons. $\boldsymbol{D}$, Example of cresyl violet-stained spinal cord cross section at the injury epicenter to show extend of injury with highlighted spared white matter. $\boldsymbol{E}$, Summary of results demonstrating a significantly higher number of labeled cells in L1-L2 segment of NG2-Ab-treated animals compared with control-Ab-treated or HX-only animals. $\boldsymbol{F}$, Summary of results demonstrating a significantly higher $5-\mathrm{HT}+$ area in L1-L5 segments in NG2-Ab versus control-Ab animals. Asterisks represent significant difference between corresponding graphs ( $p<0.05)$. Number of animals in each group after exclusion is denoted in Results.
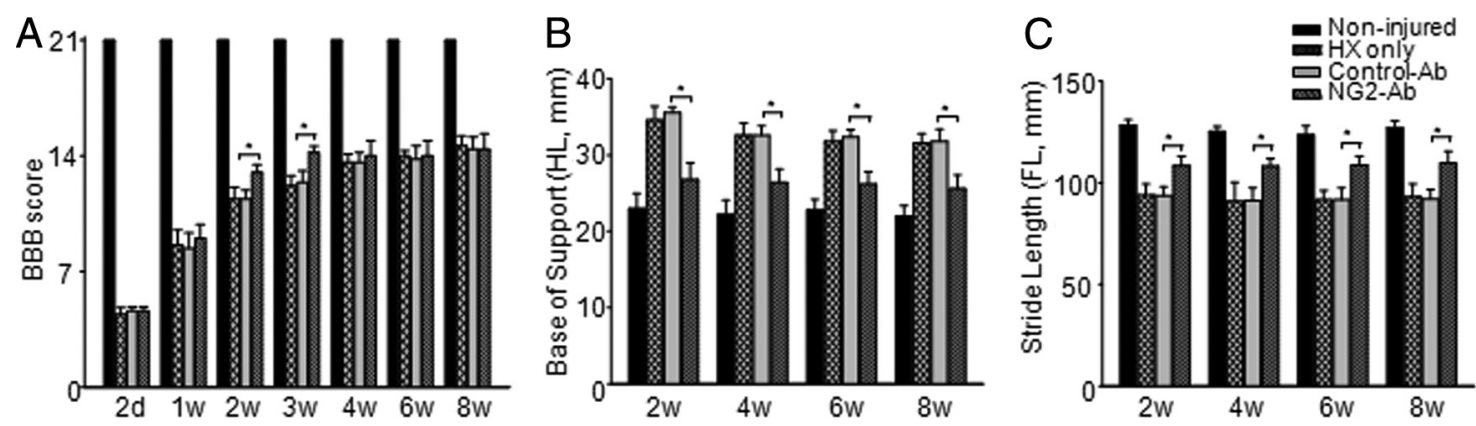

Figure 6. Effect of NG2-Ab treatment on locomotor function after chronic HX injury. A, BBB open-field locomotor scores. At $2 \mathrm{~d}$ postinjury, animals from both groups showed similar scores, indicating consisten cy of injury. At 2 and 3 weeks postinjury, NG2-Ab-treated animals showed significantly better performance compared with control-Ab-treated rats. Starting at 4 weeks, however, no significant difference was found between groups in BBB score. B, CatWalk gait analysis showed that treatment with NG2-Ab improved base of support of hindlimbs. C, CatWalk gait analysis showed that NG2-Ab-treated group demonstrated significant improvement in stride length of forelimbs compared with control-Ab-treated and HX-only groups. Asterisks represent significant difference between corresponding bars $(p<0.05)$. Note that results of CatWalk analysis demonstrate that, beginning from 2 weeks and through 8 weeks postinjury (last time point of experiment), animals from NG2-Ab group showed significant improvement of function compared with control-Ab-treated or HX-only group. Note that control-Ab-treated group did not show any difference versus $\mathrm{HX}$-only group on any test.

the robust spontaneous recovery of locomotor function that takes place after this type of injury (Courtine et al., 2008; Arvanian et al., 2009; Schnell et al., 2011b). Therefore all animals were also tested in more sensitive tests.

CatWalk gait analysis

Gait parameters are considered to be a sensitive assessment of locomotor function in the case of HX SCI (García-Alías et al., 2011). We therefore measured locomotor function using the Cat-
Walk device starting from week 2, when weight-support stepping of four paws was evident. All injured animals showed significant impairment compared with noninjured animals (Fig. 6). Control-Ab-treated and HX nontreated animals showed same impairment and similar pattern of recovery in both base-ofsupport distance (HX injury only: $31.6 \pm 1.2 \mathrm{~mm}$; HX/controlAb: $31.8 \pm 1.8 \mathrm{~mm}$ at 8 weeks postinjury; noninjured, $22 \pm 1.3$ $\mathrm{mm}$ ) and stride length (HX injury only: $93.2 \pm 6.2 \mathrm{~mm}$; HX/ 
control-Ab: $92 \pm 4.7 \mathrm{~mm}$ at 8 weeks postinjury; noninjured, $127 \pm 3.4 \mathrm{~mm}$ ). NG2-Ab-treated animals showed significant improvement of function, which was evident by narrower base of support and an increase in stride length compared with control-Ab treated starting from week 2 and throughout the experiment for base of support and stride length at 8 weeks postinjury (base of support at 8 weeks postinjury: NG2-Ab, $25.6 \pm 1.8$ $\mathrm{mm}$; control-Ab, $31.8 \pm 1.5 \mathrm{~mm}, p<0.05$; Fig. $6 \mathrm{~A}$; stride length at 8 weeks postinjury: NG2-Ab, $109.6 \pm 5.9 \mathrm{~mm}$; control-Ab, $92 \pm 4.7 \mathrm{~mm}, p<0.05$; Fig. $6 B)$.

\section{Discussion}

Here, we demonstrated that (1) acute administration of NG2-Ab prevented the acute blocking effects of exogenous NG2 on axonal conduction and that (2) chronic infusion of NG2-Ab using osmotic minipumps improved transmission to lumbar L5 motoneurons through spared VLF axons in chronically injured spinal cord. Consistent with the beneficial effects of NG2-Ab on synaptic transmission in damaged spinal cord, NG2-Ab treatment increased the excitability of these axons, promoted anatomical plasticity in lumbar segments, and improved locomotor recovery.

Because CSPGs are essential components of the extracellular matrix, neutralization of a single CSPG family member has been proposed to be more beneficial than degrading all CSPGs (Zhou et al., 2001; Brakebusch et al., 2002; Bartus et al., 2012). Among the CSPGs elevated in the vicinity of the glial scar, NG2 has been implicated as a major obstacle to axonal regeneration following brain and spinal cord injury (Levine, 1994; Fidler et al., 1999; Jones et al., 2002). In addition to its function as a key inhibitory molecule of axonal regeneration and sprouting, NG2 was found to block axonal conduction (Hunanyan et al., 2010). The results of the current study revealed that acute intraspinal injections of NG2-Ab, before injections of NG2, prevent the ability of NG2 to block axonal conduction (Fig. 1). These results strongly suggest that delivery of NG2-Ab may be a potent tool for the neutralization of the inhibitory function of NG2 on axonal conduction leading to increased synaptic plasticity in spinal circuits where levels of NG2 are elevated.

\section{Effects of NG2-Ab in chronically HX-injured spinal cord}

Results of the current study demonstrate that chronic administration of NG2-Ab improved diminished synaptic transmission to lumbar L5 motoneurons through spared VLF axons (Fig. 2), most probably by enhancing excitability of these axons (Fig. 3) and by promoting anatomical plasticity (Fig. 5) after chronic HX injury. The effects of NG2-Ab on synaptic plasticity in lumbar segments of the damaged spinal cord were tightly correlated with the effects of NG2-Ab on anatomical plasticity. Using anatomical tracing and 5-HT immunoreactivity, we found an increased number of FR retrogradely labeled cells and an increased density of 5-HT + fibers in lumbar segments in chronically HX-injured and NG2-Ab-treated animals (Fig. 5).

Enhanced transmission to L5 motoneurons through uncut VLF fibers spanning the injury epicenter (Fig. 2) and improvements in both synaptic plasticity (Fig. 2) and anatomical plasticity (Fig. 5) in the lumbar circuits are associated with better functional recovery in the chronic NG2-Ab-treated animals (Fig. 6). The importance of improved plasticity in the lumbar circuitry cannot be underestimated. In damaged spinal cord, supraspinal regeneration is absent or minimal (Houle, 1991; Xu et al., 1995, Guest et al., 1997). Thus, the goal of enhancing the regeneration of damaged propriospinal fibers around the lesion (Bareyre et al.,
2004) or sprouting of spared propriospinal axons caudal to the injury epicenter (Courtine et al., 2008) are more achievable alternatives for recovery of function after injury. L5 motoneurons in the adult rat lumbar spinal cord directly innervate the hindlimb muscles (White and Barnes, 1975). More rostral L1-L2 segments contain critical central pattern generator circuitry (NicolopoulosStournaras and Iles, 1983; Cazalets et al., 1995; Magnuson et al., 1999; Rossignol et al., 2006) and play a key role in the recovery of hindlimb locomotion after complete spinal cord transection (Gerasimenko et al., 2002; Edgerton et al., 2004; Boyce et al., 2012) and partial injuries (Barrière et al., 2008). Consistent with our results demonstrating rigorous retrograde transport of FR from L5 gray matter to neurons in ipsilateral and contralateral ventral horn of L1-L2 segments (Fig. 5), the descending commissural interneurons located in the rodent L2 ventral horn and projecting ipsilaterally and contralaterally to lower lumbar segments have been previously described (Butt et al., 2002). Importantly, these neurons play an essential role in coordination during locomotion (Magnuson et al., 1999; Kiehn, 2006).

Thus, improved synaptic and anatomical plasticity of the short propriospinal neurons within lumbar segments induced by NG2-Ab treatment may have translational potential for improving function after partial SCI.

How does NG2-Ab execute action on synaptic transmission? NG2 is a unique transmembrane CSPG. The short intracellular domain of NG2 binds various signaling molecules that may link NG2 to synapses and the cytoskeleton. The large extracellular domain $(290 \mathrm{kDa})$ contains at least one covalently attached chondroitin sulfate glycosaminoglycans (GAGs) disaccharide sugar chain (Nishiyama et al., 1991; Stallcup, 2002; Trotter et al., 2010). The cleavage of the GAGs from the protein core with $\mathrm{Ch}-\mathrm{ABC}$ can partially neutralize the inhibitory nature of NG2 on the neurite growth and on the growth-cone collapse (Ughrin et al., 2003; Laabs et al., 2007). The core protein of NG2 also contributes to the inhibition of neurite growth (Dou and Levine, 1994; Chen et al., 2002; Ughrin et al., 2003; Yiu and He, 2006). In vivo, the treatment with NG2-Ab that binds and neutralizes the NG2 proteoglycan was found to induce regeneration and growth of mechanosensory axons into the nonpermissive environment of the glial scar (Tan et al., 2006, 2007).

The inhibitory function of NG2 on axonal conduction is associated with an accumulation of CSPGs in the vicinity of HX injury (García-Alías et al., 2011). In the peripheral nervous system, deposition of NG2 was found at nodes of Ranvier (Martin et al., 2001). In CNS, NG2 has been detected on the surface of oligodendrocyte precursor cells (Levine and Nishiyama, 1996), which are known to have processes at nodes of Ranvier (Butt et al., 1999). However, the functional significance of presence of NG2 in close contact with the nodes is unknown. Our current experiments using double immunostaining with Caspr/NG2 and Caspr $/ \mathrm{Na}^{+}$channels revealed NG2-positive processes within nodal gap in many nodes of Ranvier at the location of $\mathrm{Na}^{+}$channel clusters within these nodes (Fig. 4), which are known to be directly involved in propagation of action potentials along the spinal cord axons (Wang et al., 1997; Black et al., 2006). We hypothesize that NG2-Ab may bind to NG2 on glial cell surfaces and in the extracellular matrix and may prevent an interaction of critical regions of the NG2 core protein with neurons and axonal nodes in the damaged spinal cord and may thus neutralize the inhibitory function of NG2 on axonal conduction. Alternatively, binding of the antibody to NG2 stimulate internalization and/or phagocytosis of antigen-antibody complexes reducing the accu- 
mulation of NG2 at cell surfaces and in the extracellular matrix. Further investigation is needed to better understand the molecular and cellular mechanisms underlying the inhibitory function of NG2 on axonal conduction and synaptic transmission, as well as the molecular and cellular mechanisms that enable NG2-Ab to block that function.

\section{Expectations to further improve effects of NG2-Ab on recovery}

Our results demonstrate that treatment with NG2-Ab appears to be an excellent approach for enhancing anatomical and synaptic plasticity in lumbar spinal cord following HX injury. However, treatment with NG2-Ab alone did not affect the negligible number cells in thoracic T4-T7 segments projecting to L5 and induced minor (although sufficient) improvement of locomotor function.

Consistent with these limited effects of NG2-Ab alone on locomotor function, treatment with $\mathrm{Ch}-\mathrm{ABC}$ alone, although found to improve axonal sprouting, induced little or no recovery of locomotor function following contusion SCI (Tom et al., 2009; Harris et al., 2010) and lateral HX injury at thoracic (Hunanyan et al., 2010) and cervical (Alilain et al., 2011) levels. More promising therapies for spinal cord repair can be expected when strategies incorporating inhibition of CSPGs are combined with neurotrophic support (Massey et al., 2008; Lee et al., 2010; García-Alías et al., 2011), peripheral nerve graft implantation (Houle et al., 2006; Karimi-Abdolrezaee et al., 2010; Alilain et al., 2011), or rehabilitation (García-Alías et al., 2009, García-Alías and Fawcett, 2012). Restoring function after spinal cord injury through the multipronged approach of combining NG2-Ab with neurotrophin delivery and/or rehabilitation is our next task.

In conclusion, our results demonstrate that prolonged treatment with NG2-Ab may be an excellent tool for improving synaptic and anatomical plasticity after partial midthoracic SCI. These results provide a solid foundation for suggesting that NG2-Ab can be a very important and useful part of a combinatorial treatment. We expect that therapies based on combining neutralization of NG2 molecules with appropriate neurotrophic support will be an effective strategy to promote recovery of locomotor function.

\section{References}

Alilain WJ, Horn KP, Hu H, Dick TE, Silver J (2011) Functional regeneration of respiratory pathways after spinal cord injury. Nature 475:196-200. CrossRef Medline

Andrews EM, Richards RJ, Yin FQ, Viapiano MS, Jakeman LB (2012) Alterations in chondroitin sulfate proteoglycan expression occur both at and far from the site of spinal contusion injury. Exp Neurol 235:174-187. CrossRef Medline

Arvanian VL, Manuzon H, Davenport M, Bushell G, Mendell LM, Robinson JK (2006) Combined treatment with neurotrophin-3 and LSD facilitates behavioral recovery from double-hemisection spinal injury in neonatal rats. J Neurotrauma 23:66-74. CrossRef Medline

Arvanian VL, Schnell L, Lou L, Golshani R, Hunanyan A, Ghosh A, Pearse DD, Robinson JK, Schwab ME, Fawcett JW, Mendell LM (2009) Chronic spinal hemisection in rats induces a progressive decline in transmission in uninjured fibers to motoneurons. Exp Neurol 216:471-480. CrossRef Medline

Ballermann M, Fouad K (2006) Spontaneous locomotor recovery in spinal cord injured rats is accompanied by anatomical plasticity of reticulospinal fibers. Eur J Neurosci 23:1988-1996. CrossRef Medline

Bareyre FM, Kerschensteiner M, Raineteau O, Mettenleiter TC, Weinmann O, Schwab ME (2004) The injured spinal cord spontaneously forms a new intraspinal circuit in adult rats. Nat Neurosci 7:269-277. CrossRef Medline

Barrière G, Leblond H, Provencher J, Rossignol S (2008) Prominent role of the spinal central pattern generator in the recovery of locomotion after partial spinal cord injuries. J Neurosci 28:3976-3987. CrossRef Medline

Barritt AW, Davies M, Marchand F, Hartley R, Grist J, Yip P, McMahon SB, Bradbury EJ (2006) Chondroitinase ABC promotes sprouting of intact and injured spinal systems after spinal cord injury. J Neurosci 26:1085610867. CrossRef Medline

Bartus K, James ND, Bosch KD, Bradbury EJ (2012) Chondroitin sulphate proteoglycans: key modulators of spinal cord and brain plasticity. Exp Neurol 235:5-17. CrossRef Medline

Basso DM, Beattie MS, Bresnahan JC (1995) A sensitive and reliable locomotor rating scale for open field testing in rats. J Neurotrauma 12:1-21. CrossRef Medline

Black JA, Waxman SG, Smith KJ (2006) Remyelination of dorsal column axons by endogenous Schwann cells restores the normal pattern of Nav1.6 and Kv1.2 at nodes of Ranvier. Brain 129:1319-1329. CrossRef Medline

Blight AR (1983) Axonal physiology of chronic spinal cord injury in the cat: intracellular recording in vitro. Neuroscience 10:1471-1486. CrossRef Medline

Boyce VS, Park J, Gage FH, Mendell LM (2012) Differential effects of brainderived neurotrophic factor and neurotrophin- 3 on hindlimb function in paraplegic rats. Eur J Neurosci 35:221-232. CrossRef Medline

Bradbury EJ, Moon LD, Popat RJ, King VR, Bennett GS, Patel PN, Fawcett JW, McMahon SB (2002) Chondroitinase ABC promotes functional recovery after spinal cord injury. Nature 416:636-640. CrossRef Medline

Brakebusch C, Seidenbecher CI, Asztely F, Rauch U, Matthies H, Meyer H, Krug M, Böckers TM, Zhou X, Kreutz MR, Montag D, Gundelfinger ED, Fässler R (2002) Brevican-deficient mice display impaired hippocampal CA1 long-term potentiation but show no obvious deficits in learning and memory. Mol Cell Biol 22:7417-7427. CrossRef Medline

Butt AM, Duncan A, Hornby MF, Kirvell SL, Hunter A, Levine JM, Berry M (1999) Cells expressing the NG2 antigen contact nodes of Ranvier in adult CNS white matter. Glia 26:84-91. CrossRef Medline

Butt SJ, Harris-Warrick RM, Kiehn O (2002) Firing properties of identified interneuron populations in the mammalian hindlimb central pattern generator. J Neurosci 22:9961-9971. Medline

Caggiano AO, Zimber MP, Ganguly A, Blight AR, Gruskin EA (2005) Chondroitinase $\mathrm{ABCI}$ improves locomotion and bladder function following contusion injury of the rat spinal cord. J Neurotrauma 22:226-239. CrossRef Medline

Cazalets JR, Borde M, Clarac F (1995) Localization and organization of the central pattern generator for hindlimb locomotion in newborn rat. J Neurosci 15:4943-4951. Medline

Chen ZJ, Negra M, Levine A, Ughrin Y, Levine JM (2002) Oligodendrocyte precursor cells: reactive cells that inhibit axon growth and regeneration. J Neurocytol 31:481-495. CrossRef Medline

Conta AC, Stelzner DJ (2004) Differential vulnerability of propriospinal tract neurons to spinal cord contusion injury. J Comp Neurol 479:347359. CrossRef Medline

Courtine G, Song B, Roy RR, Zhong H, Herrmann JE, Ao Y, Qi J, Edgerton VR, Sofroniew MV (2008) Recovery of supraspinal control of stepping via indirect propriospinal relay connections after spinal cord injury. Nat Med 14:69-74. CrossRef Medline

Davies SJ, Fitch MT, Memberg SP, Hall AK, Raisman G, Silver J (1997) Regeneration of adult axons in white matter tracts of the central nervous system. Nature 390:680-683. Medline

Dou CL, Levine JM (1994) Inhibition of neurite growth by the NG2 chondroitin sulfate proteoglycan. J Neurosci 14:7616-7628. Medline

Edgerton VR, Tillakaratne NJ, Bigbee AJ, de Leon RD, Roy RR (2004) Plasticity of the spinal neural circuitry after injury. Annu Rev Neurosci 27 : 145-167. CrossRef Medline

Fawcett JW, Asher RA (1999) The glial scar and central nervous system repair. Brain Res Bull 49:377-391. CrossRef Medline

Feinberg K, Eshed-Eisenbach Y, Frechter S, Amor V, Salomon D, Sabanay H, Dupree JL, Grumet M, Brophy PJ, Shrager P, Peles E (2010) A glial signal consisting of gliomedin and NrCAM clusters axonal $\mathrm{Na}+$ channels during the formation of nodes of Ranvier. Neuron 65:490-502. CrossRef Medline

Fidler PS, Schuette K, Asher RA, Dobbertin A, Thornton SR, Calle-Patino Y, Muir E, Levine JM, Geller HM, Rogers JH, Faissner A, Fawcett JW (1999) Comparing astrocytic cell lines that are inhibitory or permissive for axon growth: the major axon-inhibitory proteoglycan is NG2. J Neurosci 19: 8778-8788. Medline 
Galtrey CM, Fawcett JW (2007) The role of chondroitin sulfate proteoglycans in regeneration and plasticity in the central nervous system. Brain Res Rev 54:1-18. CrossRef Medline

García-Alías G, Fawcett JW (2012) Training and anti-CSPG combination therapy for spinal cord injury. Exp Neurol 235:26-32. CrossRef Medline

García-Alías G, Barkhuysen S, Buckle M, Fawcett JW (2009) Chondroitinase $\mathrm{ABC}$ treatment opens a window of opportunity for task-specific rehabilitation. Nat Neurosci 12:1145-1151. CrossRef Medline

García-Alías G, Petrosyan HA, Schnell L, Horner PJ, Bowers WJ, Mendell LM, Fawcett JW, Arvanian VL (2011) Chondroitinase ABC combined with neurotrophin NT-3 secretion and NR2D expression promotes axonal plasticity and functional recovery in rats with lateral hemisection of the spinal cord. J Neurosci 31:17788-17799. CrossRef Medline

Gerasimenko YP, Makarovskii AN, Nikitin OA (2002) Control of locomotor activity in humans and animals in the absence of supraspinal influences. Neurosci Behav Physiol 32:417-423. CrossRef Medline

Guest JD, Rao A, Olson L, Bunge MB, Bunge RP (1997) The ability of human Schwann cell grafts to promote regeneration in the transected nude rat spinal cord. Exp Neurol 148:502-522. CrossRef Medline

Hains BC, Johnson KM, McAdoo DJ, Eaton MJ, Hulsebosch CE (2001) Engraftment of serotonergic precursors enhances locomotor function and attenuates chronic central pain behavior following spinal hemisection injury in the rat. Exp Neurol 171:361-378. CrossRef Medline

Hamers FP, Lankhorst AJ, van Laar TJ, Veldhuis WB, Gispen WH (2001) Automated quantitative gait analysis during overground locomotion in the rat: its application to spinal cord contusion and transection injuries. J Neurotrauma 18:187-201. CrossRef Medline

Harris NG, Mironova YA, Hovda DA, Sutton RL (2010) Chondroitinase $\mathrm{ABC}$ enhances pericontusion axonal sprouting but does not confer robust improvements in behavioral recovery. J Neurotrauma 27:1971-1982. CrossRef Medline

Holmes GM, Van Meter MJ, Beattie MS, Bresnahan JC (2005) Serotonergic fiber sprouting to external anal sphincter motoneurons after spinal cord contusion. Exp Neurol 193:29-42. Medline

Houle JD (1991) Demonstration of the potential for chronically injured neurons to regenerate axons into intraspinal peripheral nerve grafts. Exp Neurol 113:1-9. CrossRef Medline

Houle JD, Tom VJ, Mayes D, Wagoner G, Phillips N, Silver J (2006) Combining an autologous peripheral nervous system "bridge" and matrix modification by chondroitinase allows robust, functional regeneration beyond a hemisection lesion of the adult rat spinal cord. J Neurosci 26: 7405-7415. CrossRef Medline

Hunanyan AS, García-Alías G, Alessi V, Levine JM, Fawcett JW, Mendell LM, Arvanian VL (2010) Role of chondroitin sulfate proteoglycans in axonal conduction in Mammalian spinal cord. J Neurosci 30:7761-7769. CrossRef Medline

Hunanyan AS, Alessi V, Patel S, Pearse DD, Matthews G, Arvanian VL (2011) Alterations of action potentials and the localization of Nav1.6 sodium channels in spared axons after hemisection injury of the spinal cord in adult rats. J Neurophysiol 105:1033-1044. CrossRef Medline

Hunanyan AS, Petrosyan HA, Alessi V, Arvanian VL (2012) Repetitive spinal electromagnetic stimulation opens a window of synaptic plasticity in damaged spinal cord: role of NMDA receptors. J Neurophysiol 107:30273039. CrossRef Medline

Jeong MA, Plunet W, Streijger F, Lee JH, Plemel JR, Park S, Lam CK, Liu J, Tetzlaff W (2011) Intermittent fasting improves functional recovery after rat thoracic contusion spinal cord injury. J Neurotrauma 28:479-492. CrossRef Medline

Jones LL, Yamaguchi Y, Stallcup WB, Tuszynski MH (2002) NG2 is a major chondroitin sulfate proteoglycan produced after spinal cord injury and is expressed by macrophages and oligodendrocyte progenitors. J Neurosci 22:2792-2803. Medline

Jordan LM, Liu J, Hedlund PB, Akay T, Pearson KG (2008) Descending command systems for the initiation of locomotion in mammals. Brain Res Rev 57:183-191. CrossRef Medline

Karimi-Abdolrezaee S, Eftekharpour E, Wang J, Schut D, Fehlings MG (2010) Synergistic effects of transplanted adult neural stem/progenitor cells, chondroitinase, and growth factors promote functional repair and plasticity of the chronically injured spinal cord. J Neurosci 30:1657-1676. CrossRef Medline

Kiehn O (2006) Locomotor circuits in the mammalian spinal cord. Annu Rev Neurosci 29:279-306. CrossRef Medline
Kim BG, Dai HN, Lynskey JV, McAtee M, Bregman BS (2006) Degradation of chondroitin sulfate proteoglycans potentiates transplant-mediated axonal remodeling and functional recovery after spinal cord injury in adult rats. J Comp Neurol 497:182-198. CrossRef Medline

Kocsis JD, Waxman SG (1980) Absence of potassium conductance in central myelinated axons. Nature 287:348-349. CrossRef Medline

Kocsis JD, Waxman SG (1982) Intra-axonal recordings in rat dorsal column axons: membrane hyperpolarization and decreased excitability precede the primary afferent depolarization. Brain Res 238:222-227. CrossRef Medline

Laabs TL, Wang H, Katagiri Y, McCann T, Fawcett JW, Geller HM (2007) Inhibiting glycosaminoglycan chain polymerization decreases the inhibitory activity of astrocyte-derived chondroitin sulfate proteoglycans. J Neurosci 27:14494-14501. CrossRef Medline

Lee H, McKeon RJ, Bellamkonda RV (2010) Sustained delivery of thermostabilized chABC enhances axonal sprouting and functional recovery after spinal cord injury. Proc Natl Acad Sci U S A 107:3340-3345. CrossRef Medline

Lemons ML, Howland DR, Anderson DK (1999) Chondroitin sulfate proteoglycan immunoreactivity increases following spinal cord injury and transplantation. Exp Neurol 160:51-65. CrossRef Medline

Levine JM (1994) Increased expression of the NG2 chondroitinsulfate proteoglycan after brain injury. J Neurosci 14:4716-4730. Medline

Levine JM, Nishiyama A (1996) The NG2 chondroitin sulfate proteoglycan: a multifunctional proteoglycan associated with immature cells. Perspect Dev Neurobiol 3:245-259. Medline

Liebscher T, Schnell L, Schnell D, Scholl J, Schneider R, Gullo M, Fouad K, Mir A, Rausch M, Kindler D, Hamers FP, Schwab ME (2005) Nogo-A antibody improves regeneration and locomotion of spinal cord-injured rats. Ann Neurol 58:706-719. CrossRef Medline

Lloyd DP (1949) Post-tetanic potentiation of response in monosynaptic reflex pathways of the spinal cord. J Gen Physiol 33:147-170. CrossRef Medline

Magnuson DS, Trinder TC, Zhang YP, Burke D, Morassutti DJ, Shields CB (1999) Comparing deficits following excitotoxic and contusion injuries in the thoracic and lumbar spinal cord of the adult rat. Exp Neurol 156: 191-204. CrossRef Medline

Martin S, Levine AK, Chen ZJ, Ughrin Y, Levine JM (2001) Deposition of the NG2 proteoglycan at nodes of Ranvier in the peripheral nervous system. J Neurosci 21:8119-8128. Medline

Massey JM, Amps J, Viapiano MS, Matthews RT, Wagoner MR, Whitaker CM, Alilain W, Yonkof AL, Khalyfa A, Cooper NG, Silver J, Onifer SM (2008) Increased chondroitin sulfate proteoglycan expression in denervated brainstem targets following spinal cord injury creates a barrier to axonal regeneration overcome by chondroitinase $\mathrm{ABC}$ and neurotrophin-3. Exp Neurol 209:426-445. CrossRef Medline

McKeon RJ, Schreiber RC, Rudge JS, Silver J (1991) Reduction of neurite outgrowth in a model of glial scarring following CNS injury is correlated with the expression of inhibitory molecules on reactive astrocytes. J Neurosci 11:3398-3411. Medline

Moon LD, Asher RA, Rhodes KE, Fawcett JW (2001) Regeneration of CNS axons back to their target following treatment of adult rat brain with chondroitinase ABC. Nat Neurosci 4:465-466. Medline

Nicolopoulos-Stournaras S, Iles JF (1983) Motor neuron columns in the lumbar spinal cord of the rat. J Comp Neurol 217:75-85. CrossRef Medline

Nishiyama A, Dahlin KJ, Prince JT, Johnstone SR, Stallcup WB (1991) The primary structure of NG2, a novel membrane-spanning proteoglycan. J Cell Biol 114:359-371. CrossRef Medline

Reed WR, Shum-Siu A, Onifer SM, Magnuson DS (2006) Interenlargement pathways in the ventrolateral funiculus of the adult rat spinal cord. Neuroscience 142:1195-1207. CrossRef Medline

Reed WR, Shum-Siu A, Whelan A, Onifer SM, Magnuson DS (2009) Anterograde labeling of ventrolateral funiculus pathways with spinal enlargement connections in the adult rat spinal cord. Brain Res 1302:76-84. CrossRef Medline

Rossignol S, Dubuc R, Gossard JP (2006) Dynamic sensorimotor interactions in locomotion. Physiol Rev 86:89-154. CrossRef Medline

Saruhashi Y, Young W, Perkins R (1996) The recovery of 5-HT immunoreactivity in lumbosacral spinal cord and locomotor function after thoracic hemisection. Exp Neurol 139:203-213. CrossRef Medline

Schnell L, Alessi V, Hunanyan AS, Petrosyan H, Levine JM, Mendell L, Arva- 
nian V (2011a) Decline of Fluoro Ruby (FR) retrograde transport coincides with conduction deficits through intact contralateral white matter after lateral hemisection of adult rat spinal cord. Soc Neurosci Abstr 438.02/B13.

Schnell L, Hunanyan AS, Bowers WJ, Horner PJ, Federoff HJ, Gullo M, Schwab ME, Mendell LM, Arvanian VL (2011b) Combined delivery of Nogo-A antibody, neurotrophin-3 and the NMDA-NR2d subunit establishes a functional 'detour' in the hemisected spinal cord. Eur J Neurosci 34:1256-1267. CrossRef Medline

Silver J, Miller JH (2004) Regeneration beyond the glial scar. Nat Rev Neurosci 5:146-156. CrossRef Medline

Snow DM, Lemmon V, Carrino DA, Caplan AI, Silver J (1990) Sulfated proteoglycans in astroglial barriers inhibit neurite outgrowth in vitro. Exp Neurol 109:111-130. CrossRef Medline

Stallcup WB (2002) The NG2 proteoglycan: past insights and future prospects. J Neurocytol 31:423-435. CrossRef Medline

Tan AM, Colletti M, Rorai AT, Skene JH, Levine JM (2006) Antibodies against the NG2 proteoglycan promote the regeneration of sensory axons within the dorsal columns of the spinal cord. J Neurosci 26:4729-4739. CrossRef Medline

Tan AM, Petruska JC, Mendell LM, Levine JM (2007) Sensory afferents regenerated into dorsal columns after spinal cord injury remain in a chronic pathophysiological state. Exp Neurol 206:257-268. CrossRef Medline

Tang X, Davies JE, Davies SJ (2003) Changes in distribution, cell associations, and protein expression levels of NG2, neurocan, phosphacan, brevican, versican $\mathrm{V} 2$, and tenascin-C during acute to chronic maturation of spinal cord scar tissue. J Neurosci Res 71:427-444. CrossRef Medline

Tom VJ, Kadakia R, Santi L, Houlé JD (2009) Administration of chondroitinase $\mathrm{ABC}$ rostral or caudal to a spinal cord injury site promotes anatomical but not functional plasticity. J Neurotrauma 26:2323-2333. CrossRef Medline

Trotter J, Karram K, Nishiyama A (2010) NG2 cells: properties, progeny and origin. Brain Res Rev 63:72-82. CrossRef Medline

Ughrin YM, Chen ZJ, Levine JM (2003) Multiple domains of the NG2 pro- teoglycan mediate axon growth inhibition. J Neurosci 23:175-186. Medline

van den Brand R, Heutschi J, Barraud Q, DiGiovanna J, Bartholdi K, Huerlimann M, Friedli L, Vollenweider I, Moraud EM, Duis S, Dominici N, Micera S, Musienko P, Courtine G (2012) Restoring voluntary control of locomotion after paralyzing spinal cord injury. Science 336:1182-1185. CrossRef Medline

Wang X, Messing A, David S (1997) Axonal and nonneuronal cell responses to spinal cord injury in mice lacking glial fibrillary acidic protein. Exp Neurol 148:568-576. CrossRef Medline

Waxman SG, Ritchie JM (1993) Molecular dissection of the myelinated axon. Ann Neurol 33:121-136. CrossRef Medline

Weinmann O, Schnell L, Ghosh A, Montani L, Wiessner C, Wannier T, Rouiller E, Mir A, Schwab ME (2006) Intrathecally infused antibodies against Nogo-A penetrate the CNS and downregulate the endogenous neurite growth inhibitor Nogo-A. Mol Cell Neurosci 32:161-173. CrossRef Medline

White SR, Barnes CD (1975) Spinal and spino-bulbo-spinal reflexes in rats with experimental allergic encephalomyelitis. Brain Res 84:123-128. CrossRef Medline

Xu XM, Guénard V, Kleitman N, Bunge MB (1995) Axonal regeneration into Schwann cell-seeded guidance channels grafted into transected adult rat spinal cord. J Comp Neurol 351:145-160. CrossRef Medline

Yamagata T, Saito H, Habuchi O, Suzuki S (1968) Purification and properties of bacterial chondroitinases and chondrosulfatases. J Biol Chem 243: 1523-1535. Medline

Yiu G, He Z (2006) Glial inhibition of CNS axon regeneration. Nat Rev Neurosci 7:617-627. CrossRef Medline

Zhou XH, Brakebusch C, Matthies H, Oohashi T, Hirsch E, Moser M, Krug M, Seidenbecher CI, Boeckers TM, Rauch U, Buettner R, Gundelfinger ED, Fässler R (2001) Neurocan is dispensable for brain development. Mol Cell Biol 21:5970-5978. CrossRef Medline

Zuo J, Neubauer D, Dyess K, Ferguson TA, Muir D (1998) Degradation of chondroitin sulfate proteoglycan enhances the neurite-promoting potential of spinal cord tissue. Exp Neurol 154:654-662. CrossRef Medline 